\title{
How to model rockburst seismic loads for civil engineering purposes?
}

\author{
Zbigniew Zembaty
}

Received: 23 May 2010 / Accepted: 7 April 2011 / Published online: 22 April 2011

(C) The Author(s) 2011. This article is published with open access at Springerlink.com

\begin{abstract}
Usually rockbursts from underground mining induce minor quakes of MM intensity up to V. Sometimes however the surface tremors reach level of MM epicentral intensity $I_{0}=$ VI to VIII. Since a fast industrial development often takes place in the mining areas then some seismic design rules for new buildings are needed. The main obstacle is then lack of respective design response spectrum and an unclear definition of the level of design acceleration to apply. Particularly the latter one is difficult to overcome because the rockburst ground motion records differ from natural earthquakes when it comes to their spectral properties as well as return periods. This paper presents a method how to rationally define the design acceleration so that a seismic code, e,g, Eurocode 8, can be applied in practical design procedures in the mining areas.
\end{abstract}

Keywords Mine tremors $\cdot$ Rockbursts $\cdot$ Ground motion $\cdot$ Response spectra $\cdot$ Seismic codes

\section{Introduction}

There are many types of ground motion other than earthquakes: blasts from queries induce waves in the ground which radiate hundreds and thousands of meters away from the source, exciting building vibrations (see e.g. Dowding 1996; Khandelwal and Singh 2007), traffic vibrations excite buildings in the vicinity of roads or railways (e.g. Paolucci and Spinelli 2006), rockbursts originating from deep mining or reservoir induced seismicity (Knoll 1992; Gibowicz and Kijko 1994) also produce ground motion. They occur randomly after large volumes of ground are excavated during reservoir construction. The strongest rockbursts from deep mining also occur randomly but sometimes may also be triggered purposely by special, initiating blasts.

Z. Zembaty $(\varangle)$

Opole University of Technology, ul. Mikolajczyka 5, 45-271 Opole, Poland

e-mail: z.zembaty@po.opole.pl 
Some of these motions may damage structures when they are unusually intensive. These from queries or surface mining are well studied and analyzed in the book by Dowding (1996). On the other hand large, deep mining rockburst effects are not as well studied, though they can be of much greater maximum intensity than the blast induced ground motion. The strongest rockbursts often reach magnitude $M_{L}=4$ and sometimes may even exceed $M_{L}=5$. These strongest rockbursts are listed among natural earthquakes by USGS National Earthquake Information Center in Denver (http://neic.usgs.gov) and are subject of careful analyses to differentiate them from underground nuclear explosions (see e.g. Pomeroy et al. 1982). Such magnitude with the focal depth of 1-2 km may lead to epicentral intensities of $M M$ VI to VIII. Since the vicinity of deep underground mines is often a place of intensive construction activities the problem of assessing seismic risk (see e.g. Van Eck et al. 2006) and mitigating these effects on civil engineering structures becomes important. Seismic codes (e.g. Eurocode $8,2005)$ are devoted to natural earthquakes which differ in many respects from rockburst ground motion.

This paper proposes a simple method to modify the Eurocode 8 approach to include rockburst quakes, so that a rational seismic load can be defined for civil engineering purposes. The main problem is the definition of the so called design acceleration. Deep mining and the assocated return period of the extreme tremors, used in the analyses of rockbursts, differs substantially from earthquakes which makes it impossible to use the same probabilistic approach as for the classic seismic risk analyses. Thus the main purpose of this paper is to present a method of assigning level of design acceleration for rockbursts which would be consistent with seismic code earthquake intensity level. The approach to modify Eurocode 8 is described in detail.

\section{Rockbursts and measures of their intensity on the ground surface}

There are various mechanisms of rockbursts. Generally they occur when accumulated stress from advancing mine activity, fractures rock mass. It is possible that the strongest rockbursts, which are of primary interest in this paper, are minor earthquakes induced on nearby fault by extensive mining activity. See Johnston (1992) or the monograph by Gibowicz and Kijko (1994) for explanations of the rockburst origin in technological and seismological terms. Others have compared ground motion from the largest mine induced seismicity to ground motion from an underground nuclear explosion, where the seismological mechanism resembles a shallow earthquake (Gibowicz and Kijko 1994). Typical damage to the buildings, infrastructure or equipment at or nearest epicenter include furniture toppling, damages to the lifts, characteristic structural and cosmetic cracks of the masonry buildings, cracks of the panel prefabricated buildings, and in some cases even stronger damages of the walls (see e.g. photographs from Figs. 1 and 2).

In a paper by Zembaty (2004) ground motions from rockbursts from a copper mining basin in Western Poland were analyzed in detail to define differences as well as similarities to earthquake records motions. Following the Johnston (1992) paper two, characteristic types of rockbursts were identified with respect to their surface records:

- Events of type I with rather low intensity, return period of 2-3 months, very short duration (1-2s), and Fourier spectra shifted to higher frequencies (about 20-40 Hz) similar to those from surface mining. These events are directly related with the mining activity.

- Rare events of type II (return period of 1-2 years), longer duration (about $5 \mathrm{~s}$ or more) and dominating part of Fourier spectra below $5 \mathrm{~Hz}$, similar to weak, shallow earthquakes. These events are only loosely connected to specific mine activity. 


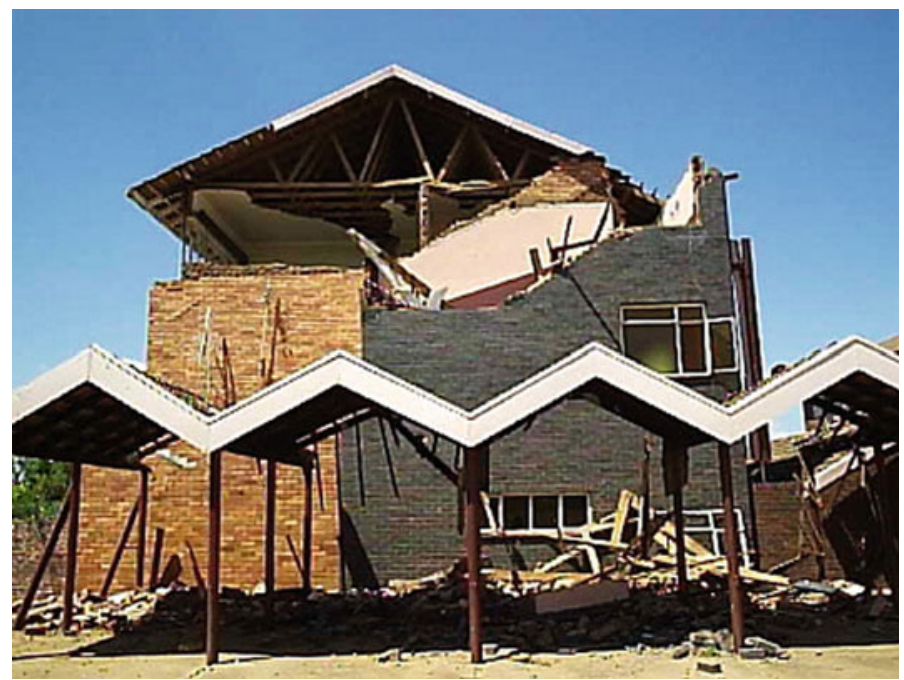

Fig. 1 Damage to brick masonry wall caused by $M_{\mathrm{L}} 5.3$ rockburst from March 9, 2005 in Stilfontein, South Africa (courtesy of A. Cichowicz)

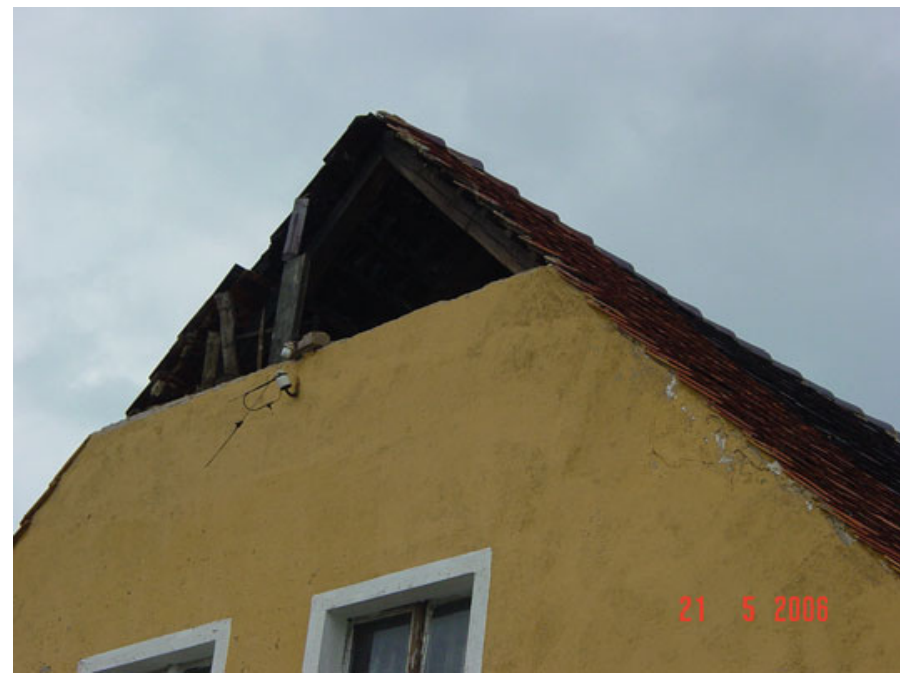

Fig. 2 Damage to a gable wall caused by $M_{\mathrm{L}} 4.3$ rockburst from May 21, 2006 in Polkowice, Poland (approximately $600 \mathrm{~m}$ from epicenter)

In Fig. 3 plots of the acceleration, velocities and Fourier spectra of a strong type II rockburst record are presented. According to USGS, the moment magnitude of this mining induced event equaled 4.8. Corrected magnitude, accounting for shallow ( $1 \mathrm{~km}$ deep) focus equaled 4.3 (according to Institute of Geophysics, Polish Academy of Sciences, Warsaw). For the record 

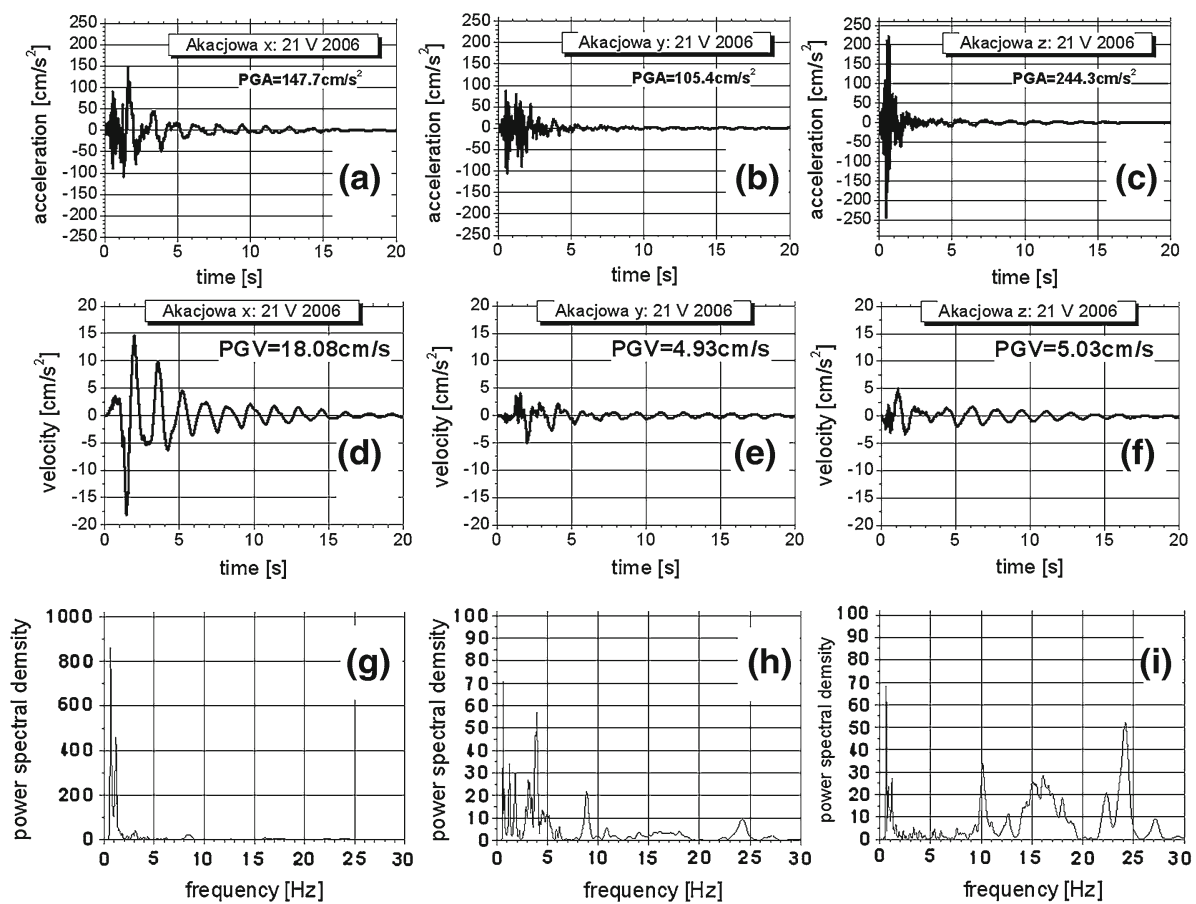

Fig. 3 Example of strong rockburst record of the event from May 21, 2006 in Polkowice, Poland, station Akacjowa Street ( $a, b$ horizontal acceleration, $d, e$ velocity, $g, h$ acceleration power spectral densities, $c, f$ vertical acceleration and velocity, $i$ vertical acceleration power spectral density)

from Fig. 3 the maximum horizontal acceleration $\mathrm{PGA}_{\text {hor }}{ }^{1}$ reached $156.7 \mathrm{~cm} / \mathrm{s}^{2}$, maximum horizontal velocity $\mathrm{PGV}_{\text {hor }}^{1}$ equaled $18.09 \mathrm{~cm} / \mathrm{s}$. In Fig. 4 respective acceleration, velocity and displacement response spectra of the time history record from Fig. 3 are shown for damping ratio 5\%. The rockburst record from Fig. 3 resembles with some respect a near field natural earthquake record in mini scale. A clear acceleration pulse along the $x$ axis can be seen. A substantial shift to high frequencies can be seen in the vertical component. The strong motion duration of the horizontal components equaled $5.3 \mathrm{~s}$. This duration is the time for cumulative Arias (1970) intensity

$$
\begin{aligned}
& I_{A}^{\mathrm{hor}}(t)=\frac{1}{2} \int_{0}^{t}\left[a_{x}^{2}(\tau)+a_{y}^{2}(\tau)\right] d \tau \\
& I_{A}^{\mathrm{ver}}(t)=\int_{0}^{t} a_{z}^{2}(\tau) d \tau
\end{aligned}
$$

to stay between 5 and $95 \%$ either for the two, horizontal components of ground acceleration $a_{x}$ and $a_{y}$ or for the vertical component $a_{z}$ (Trifunac and Brady 1975b). This $5.3 \mathrm{~s}$ strong motion duration is characteristic of mine induced seismic event.

\footnotetext{
${ }^{1}$ Horizontal maximum of two, perpendicular signals $\mathrm{x}(t)$ and $y(t)$ is defined as $\max \sqrt{\left[x(t)^{2}+y(t)^{2}\right]}$.
} 
Fig. 4 Acceleration, velocity and (relative) displacement response spectra of strong rockburst record from Fig. 3 (May 21st, 2006, Polkowice)
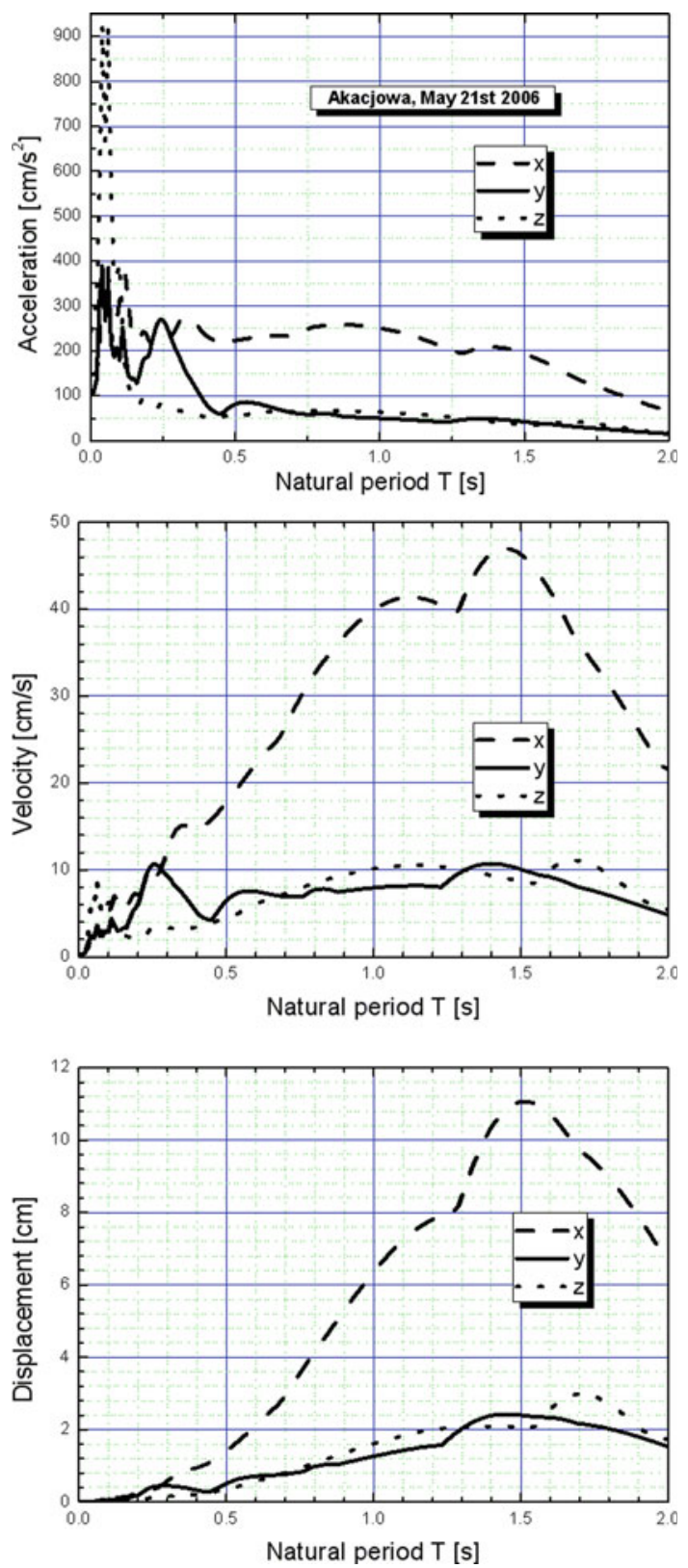

\section{Statement of the problem}

For natural earthquakes civil engineering codes of practice like Eurocode 8 or Uniform Building Code are well developed and expected seismic loads can be calculated as function of the averaged, design response spectrum model and respective design acceleration. 
However when it comes to rockbursts the application of these codes in any design practice faces two unknowns

- choice of the appropriate response spectrum to account for details of the time history

- choice of the design ground acceleration $a_{\mathrm{g}}$.

The first unknown can be found from records, since mines and their vicinity are nowadays well instrumented. Only the strong records of type II rockbursts should be analyzed (the high frequency rockbursts type I are practically harmless to buildings except only for cosmetic cracks in the plaster). After collecting enough number of such the records and carrying out well known processing and averaging techniques (e.g. Chopra 1995) the design response spectrum can be defined.

However the second unknown is more difficult to define because in seismic codes the reference, design acceleration $a_{\mathrm{gR}}$ is a probabilistic value-usually assumed as a value of maximum allowable acceleration expected to be exceeded with probability $10 \%$ during 50 years, which corresponds to 475 years return period. Such a long time span cannot be accepted to the rockbursts effects. Typical, moderate rockburts occur during mine exploitation every 1-4 months (rockbursts of type 1). The strongest, type II rockbursts occur with return period of 1-3 years. In addition the number of records of strong, type II rockbursts are limited and are not supported with studies that associate PGA with cracking damage. To solve this problem first the problem of an intensity measure of earthquakes and rockbursts should be addressed.

There are various measures of seismic intensity. To mention just a few of them:

- descriptive, 12 degree scales like the MM, MSK-64, EMS-98 etc.

- measures based on cumulative energies at the site, e.g. the Arias intensity (Eq. 1)

- measures based on peak values of seismic records (e.g. PGA, PGA hor, PGV, PGV hor)

In seismic codes each zone is defined by the design seismic acceleration. As an engineering "rule of thumb" one can even associate the design accelerations with some values of Modified Mercalli intensity: $0.05 \mathrm{~g}$ with VI MM, $0.1 \mathrm{~g}$ with VII MM, $0.2 \mathrm{~g}$ with VIII MM, $0.4 \mathrm{~g}$ with IX MM (Hadjian 1993). In Eurocode 8 the design intensity is reflected by value of the reference design acceleration $a_{\mathrm{gR}}$ which is obtained after detailed and careful studies of seismic risk in a particular country and given in National Annexes to Eurocode 8 (Garcia-Mayordomo et al. 2004). It should be pointed out here that actual design methods applied in modern codes allow the structure to respond to a rare earthquake with substantial level of damage controlled by ductility coefficient $q$. This cannot be accepted for the strong rockburst effects which may occurr with return period 2-4 years. On the other hand assumption of linear response (no damages allowed) may lead to very conservative design. Thus some selected low values of $q$ factors should be allowed.

It is well known for a long time (e.g. DIN 41-50 1975; Khandelwal and Singh 2007; Lu et al. 2002), that for the artificial seismic effects, like blasts in queries, pile hammering, traffic vibrations, the role of a "good" measure of intensity is played by peak ground velocity $(P G V)$, sometimes called Peak Particle Velocity $(P P V)$. It is so because acceleration records of seismic effects originating at very short distances are usually dominated by high frequencies. For instance a PGA of $1.5 \mathrm{~g}$ does not cause cracking at a frequency of $50 \mathrm{~Hz}$ (Siskind et al. 1980). As an effect, for some short distance blasts, the $P G A$ can reach values even close to $1 \mathrm{~g}$ but with only minor damages to the buildings. On the other hand the Peak Ground Velocity better reflects the actual severity of ground vibrations at the building site so it is much better correlated with the structural damages (Dowding 1996).

When it comes to rockbursts the role of PGV still is important, particularly for the type I rockbursts (Zembaty 2004; Johnston 1992). Also for the type II rockbursts or natural earthquakes $P G V$ can be employed as a measure of cracking damage for PGVs for dominant 
frequencies of $2-3 \mathrm{~Hz}$ and above. In addition activity of the mines is closely monitored and the expected values of peak velocity can be forecasted depending on the type and direction of underground ore exploitation. Zones, with special design requirements related to forecasted surface velocities can be defined in the areas of the mine exploitations. These maximum ground velocity estimations can be used as intensity measures for the structural design purposes. The key question is however how to link the expected surface ground velocity $v_{\mathrm{g}}$ with the code design acceleration $a_{\mathrm{g}}$.

One of the best parameters measuring severity of seismic response of structures can be structural relative displacement (e.g. interstory drift). Its value directly shows to what extend the structure was excited. Thus, no matter the type of seismic record e.g. directly artificially induced, randomly triggered by rockburst or reservuar or purely natural earthquake, its ability to induce structural relative displacement describes best its intensity with respect to structural damages. In what follows a comparison of code, design acceleration $a_{\mathrm{g}}$ with the forecasted surface velocity of the rockbursts $v_{\mathrm{g}}$ will be carried out using the relative structural displacements serving as a link for these two seismic intensity measures.

\section{Compatibility of rockburst and seismic design response spectra}

Consider a single degree of freedom system under seismic excitations $U(\mathrm{t})$ (Fig. 5).

The velocity of the rocbursts which induce displacement responses of the structures similar to the displacements corresponding to the design acceleration $a_{\mathrm{g}}$ can be treated as representing similar intensity as the one assumed by the seismic code. For this purpose the familiar displacement response spectrum can be used because typically this response spectrum is assumed as relative in seismic engineering and in particular in seismic codes. Consider Fig. 6, where displacement response spectra of two rockbursts are displayed together with Eurocode 8 displacement response spectra. The EC8 displacement response spectra were calculated with the level of design accelerations $a_{\mathrm{g}}$ to best fit the rockburst displacement response spectra for natural periods representing typical buildings $(\mathrm{T}=0.5-1.5 \mathrm{~s})$ and with damping ratio $\xi=5 \%$.

The first two records represented two horizontal rockburst components with $\mathrm{PGV}_{\text {hor }}=$ $6.4 \mathrm{~cm} / \mathrm{s}$. Corresponding design accelerations $a_{\mathrm{g}}$ equaled $55 \mathrm{~cm} / \mathrm{s}^{2}$. The second fit represents two rockburst records with $\mathrm{PGV}_{\text {hor }}=11.4 \mathrm{~cm} / \mathrm{s}$ and the respective design seismic

Fig. 5 Single Degree of Freedom system under kinematic excitations

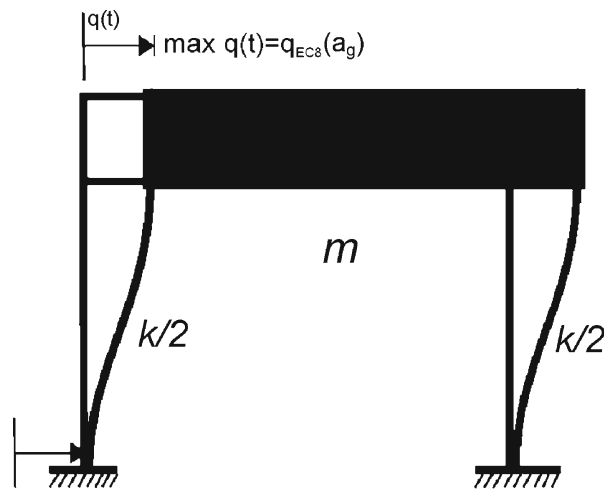

$\mathrm{U}(\mathrm{t})$ 


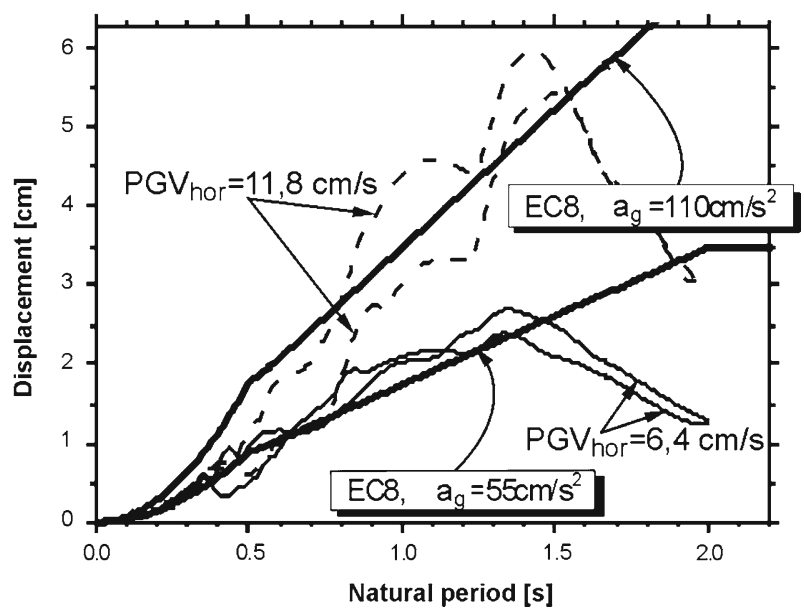

Fig. 6 Displacement response spectra of two rockburst records and respective Eurocode 8 displacement response spectra

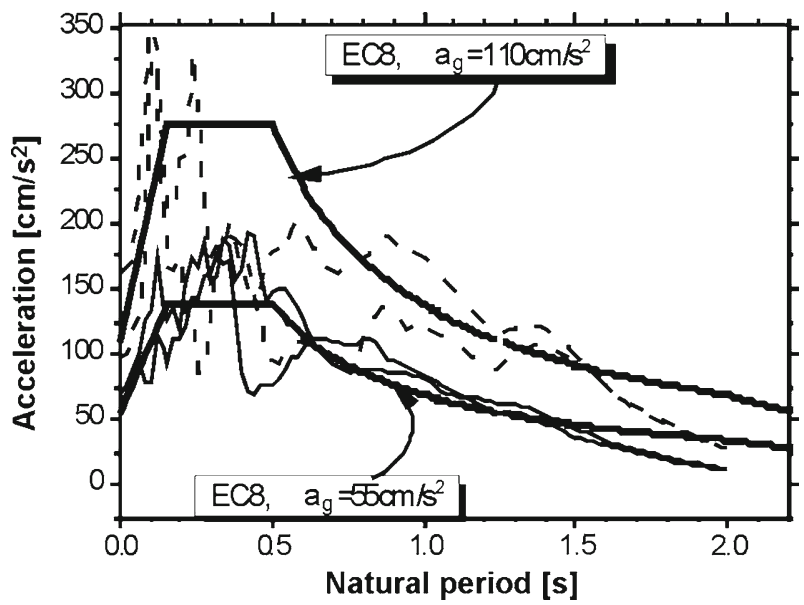

Fig. 7 Acceleration response spectra of two rockburst records and respective Eurocode 8 acceleration response spectra

acceleration $a_{\mathrm{g}}=110 \mathrm{~cm} / \mathrm{s}^{2}$. In Fig. 7 respective (absolute) acceleration response spectra of the two records used to calculate Fig. 6 are shown.

The ratio $r$ between the horizontal rockburst velocities and Eurocode 8 design accelerations are:

$$
\begin{gathered}
r=\frac{55}{6.4} \cong 8.6 \\
r=\frac{110}{11.8} \cong 9.3
\end{gathered}
$$




\section{Design, "averaged" response spectrum of rockburst excitations}

From the wide choice of rockburst records only 18 type II records were selected since only these records represented ground motion strong enough to be of interest in constructing the response spectrum. Their main parameters are shown in Table 1.

To show the variability of all the strong motion records used in the analysis respective coefficients of variation are shown at the bottom of Table 1. In addition the response spectra of all the records listed in Table 1 are shown together in Fig. 8, normalized to PGV $=1 \mathrm{~cm} / \mathrm{s}$. Such the normalization transforms all the response spectra plots into common intensity.

When constructing averaged response spectrum the accelerograms should be normalized with respect to the same peak acceleration (Fig. 9).

Next a smooth, design response spectrum was obtained (Zembaty and Kokot 2007) by applying standard averaging techniques (see e.g. Chopra 1995). This response spectrum is given by equation (4) and is displayed in Fig. 10.

Table 1 Selected parameters of the rockburst records applied in constructing the design response spectrum for the LGOM area

\begin{tabular}{|c|c|c|c|c|c|}
\hline \multirow[t]{3}{*}{ Date } & \multirow{3}{*}{$\begin{array}{l}\text { Name of the recording } \\
\text { station }\end{array}$} & \multicolumn{2}{|l|}{ Acceleration } & \multirow{2}{*}{$\begin{array}{l}\text { Velocity } \\
\text { PGV }(\mathrm{cm} / \mathrm{s})\end{array}$} & \multirow{2}{*}{$\begin{array}{l}\text { Displacement } \\
\text { PGD }(\mathrm{cm})\end{array}$} \\
\hline & & PGA $\left(\mathrm{cm} / \mathrm{s}^{2}\right)$ & Duration $t_{d}(\mathrm{~s})$ & & \\
\hline & & \multicolumn{4}{|l|}{$\begin{array}{l}\text { Horizontal } \\
\text { Vertical* }\end{array}$} \\
\hline \multirow[t]{14}{*}{ May 21st 2006} & \multirow[t]{2}{*}{ Akacjowa } & 156.7 & 4.93 & 18.09 & 3.75 \\
\hline & & 244.3 & 1.27 & 5.03 & 0.83 \\
\hline & \multirow[t]{2}{*}{3 Maja } & 191.4 & 3.04 & 9.25 & 1.67 \\
\hline & & 218.1 & 1.92 & 4.02 & 0.65 \\
\hline & \multirow[t]{2}{*}{ Miedziana (1) } & 177.5 & 3.99 & 16.21 & 2.66 \\
\hline & & 218.5 & 1.85 & 2.80 & 0.65 \\
\hline & \multirow[t]{2}{*}{ Miedziana (2) } & 133.5 & 3.98 & 17.27 & 3.00 \\
\hline & & - & - & - & - \\
\hline & \multirow[t]{2}{*}{ Hubala } & 145.8 & 3.86 & 6.83 & 1.14 \\
\hline & & 300.1 & 0.86 & 5.36 & 0.43 \\
\hline & \multirow[t]{2}{*}{ Aquapark } & 98.8 & 4.81 & 4.13 & 0.62 \\
\hline & & 126.6 & 2.26 & 2.44 & 0.22 \\
\hline & \multirow[t]{2}{*}{ Skalników } & 124.5 & 2.23 & 3.61 & 0.22 \\
\hline & & 154.7 & 1.45 & 1.89 & 0.12 \\
\hline \multirow[t]{4}{*}{ February 20th 2002} & \multirow[t]{2}{*}{ Hubala } & 74.1 & 4.96 & 6.37 & 1.23 \\
\hline & & - & - & - & - \\
\hline & \multirow[t]{2}{*}{ Miedziana (2) } & 162.2 & 5.27 & 11.98 & 2.38 \\
\hline & & - & - & - & - \\
\hline \multirow{2}{*}{\multicolumn{2}{|c|}{ Coefficient of variation }} & $27 \%$ & $24 \%$ & $55 \%$ & $63 \%$ \\
\hline & & $30 \%$ & $32 \%$ & $40 \%$ & $57 \%$ \\
\hline
\end{tabular}

* The missing fields represent overshoot records 
Fig. 8 Acceleration, velocity and displacement response spectra of the horizontal components of 18 strong records listed in Table 1. All the plots are normalized with respect to $\mathrm{PGV}=1 \mathrm{~cm} / \mathrm{s}$ (damping ratio 5\%)
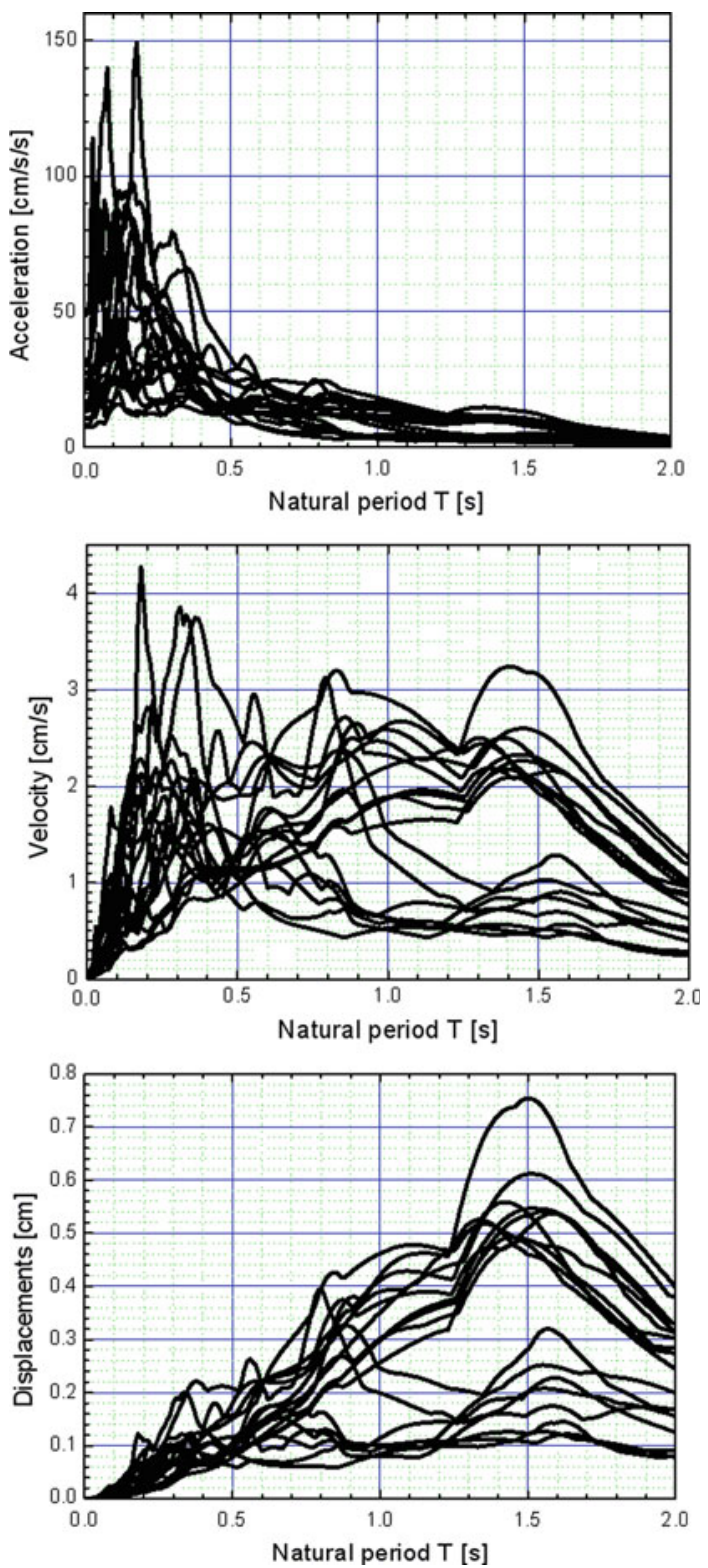

$$
S_{e}(T)=a_{g} \cdot \begin{cases}{\left[1+\frac{T}{T_{B}}(2.5 \eta-1)\right]} & 0<T<T_{B} \\ 2.5 \eta & T_{B} \leq T \leq T_{C} \\ 2.5 \eta \frac{T_{C}}{T} & T_{C}<T \leq T_{D}=a_{g} \beta(T) \\ 2.5 \eta \frac{T_{C}}{T_{D}} & T_{D}<T \leq T_{E} \\ 2.5 \eta \frac{T_{C} T_{E}^{2}}{T_{D} T^{2}} & T>T_{E}\end{cases}
$$




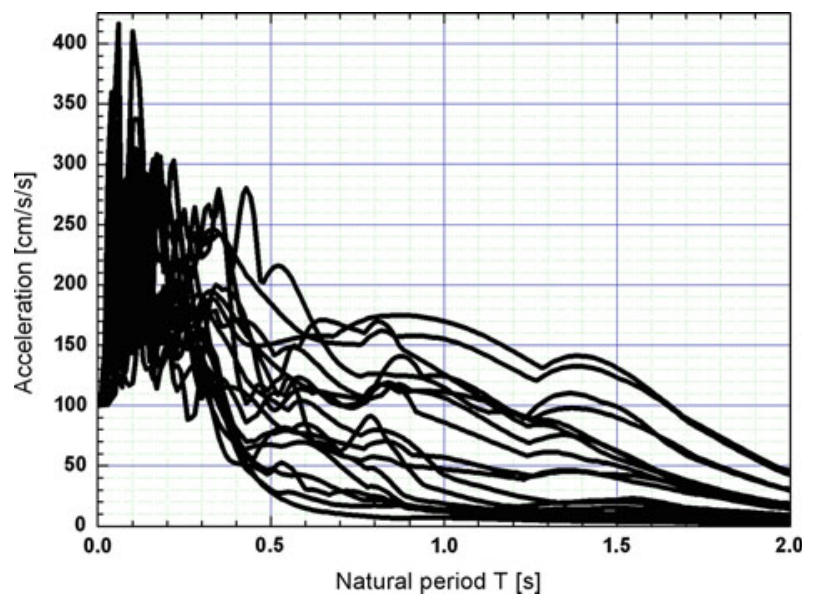

Fig. 9 Acceleration response spectra of 18 strong horizontal records from Table 1, normalized with respect to $\mathrm{PGA}=100 \mathrm{~cm} / \mathrm{s}^{2}$ (damping ratio $\left.5 \%\right)$

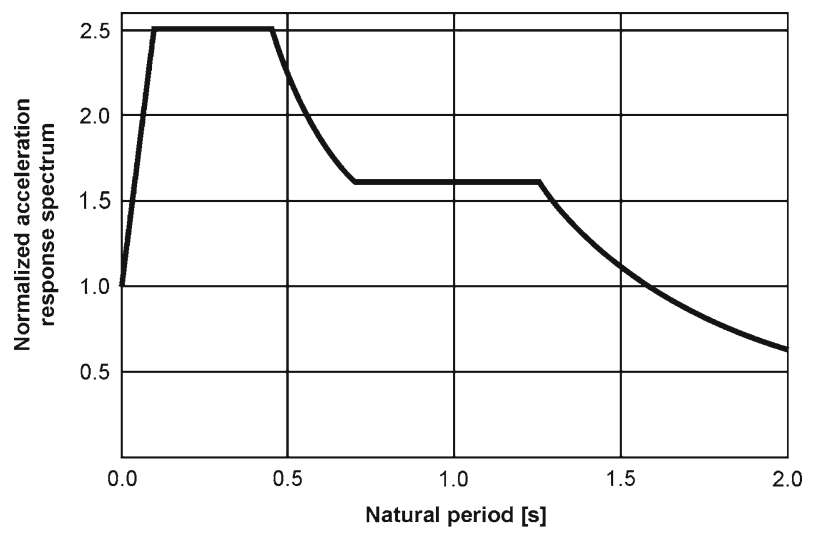

Fig. 10 Rockburst design response spectrum for 5\% damping ratio constructed using the records listed in Table 1

The design response spectrum was obtained by excluding the site effects. It was done so because the actual area of the mine activity was rather small and with relatively uniform shear wave velocity in the surface layer (Mutke et al. 2000).

\section{Dependence between the rockburst intensity and design acceleration}

Finally, the last step was to obtain the average coefficient between the forecasted ground velocity $v_{\mathrm{g}}$ and the design acceleration $a_{\mathrm{g}}$. It was done by formulating a minimization problem in which the difference between rockburst displacement response spectra $S_{\mathrm{displ}}^{\text {record }}$ and the averaged response spectrum (4) $S_{\text {displ }}^{\text {design }}$ was minimized:

$$
\left[S_{\mathrm{displ}}^{\text {record }}\left(T, v_{g}\right)-S_{\mathrm{displ}}^{\text {design }}\left(a_{g}, T\right)\right]^{2}=\min \quad \text { for natural periods } T=T_{1} \text { to } T=T_{2}
$$


The range of natural periods was chosen to include the structures which are typically planned for design in the Copper Basin LGOM in Poland, with $T_{1}=0.2 \mathrm{~s}$ and $T_{2}=1 \mathrm{~s}$.

After employing standard Matlab optimization procedures for eq. 5 and the 18 records listed in Table 1 the average coefficient between rocburst velocity $v_{\mathrm{g}}$ and design acceleration $a_{\mathrm{g}}$ was established as equal to:

$$
r=\frac{a_{\mathrm{g}}}{v_{\mathrm{g}}} \cong 8.29
$$

Typical values of horizontal velocities of strong rockbursts measured at the epicenter (with about $1000 \mathrm{~m}$ focus depth) equals from about 5 to $15 \mathrm{~cm} / \mathrm{s}$ and design accelerations $a_{\mathrm{g}}$ vary from 42 to $125 \mathrm{~cm} / \mathrm{s}^{2}$ which can be roughly associated with VI to VII MM intensity (Trifunac and Brady 1975a), particularly when taking into account usually longer durations of earthquakes than strong rockbursts. These intensity estimations are confirmed by macroscopic analyses of the data gathered during strong rockbursts in the LGOM Copper Basin (Zmbaty 2006). In terms of typical seismic codes these intensities correspond to the first, "lighter" seismic zones. In fact Eurocode 8 suggests a lower limit of about $50 \mathrm{~cm} / \mathrm{s}^{2}$ for any design seismic acceleration. For rockbursts however this limit should be lower because unlike natural earthquakes (return period 475 years) the strongest rockbursts with their return period of about 1-3 years may be expected several times during the lifetime of the building which generates greater seismic hazard for a given level of design acceleration.

Typical procedure to account for the rockburst effects in structural design consists of following steps:

a. A map of forecasted maximum horizontal ground velocities is prepared for the area affected by the deep mining (usually in radius of about $5-20 \mathrm{~km}$ around the mine). This is done by special geophysical mine services applying methods of predicting seismic hazard by probabilistic methods (e.g. Gibowicz and Kijko 1994; Kijko et al. 2001 etc.) and is based on the information about the planned underground mine activity, local attenuation law etc.

b. Based on these maps the ground surface around the mine is divided onto the velocity zones (say of maximum velocity $4,6,8 \mathrm{~cm} / \mathrm{s}$ etc.)

c. By multiplying the average "velocity-acceleration" multiplier (Eq. 6) by maximum "zone velocity" expected at the site of the designed building, respective design acceleration $a_{\mathrm{g}}$ is obtained

d. The seismic code e.g. (Eurocode 8) is applied with the design acceleration from previous point and the response spectrum shown in Fig. 10 (Eq. 4).

So far the above procedure does not account to include divers site effects and ductility $q$ factors appropriate to the return periods of strong mine tremors. In the future research there are plans to include further developments in this area.

\section{Summary and conclusions}

Rockbursts are seismic quakes belonging to the so called induced seismicity (Knoll 1992). The spectral properties of their surface records locate them somewhere between strong artificial blasts and natural earthquakes. Their epicentral intensities are similar to intensities of nuclear underground explosions while the source mechanism is more similar to natural earthquakes (Gibowicz and Kijko 1994). Since deep mining often takes place in the areas of 
urban development some measures are required to minimize the structural damages of the new, designed buildings.

For this purpose a method was developed to rationally define design seismic acceleration for rockburst actions in terms of their forecasted intensities measured by horizontal velocities. From an extended set of rockburst ground motion records 18 strong, low frequency, type II records were chosen and using standard seismic engineering methods a smooth, design response spectrum was obtained (Eq. 4, Fig. 10). The deep mining usually takes place in basins of 100-150 km size, during limited amount of time (e.g. 50-100years). For this reason it is not possible to make extensive seismic risk analyses as they are done for the areas of natural seismicity. Instead, the proposed method formulates equivalent, design acceleration level defined as the one which leads to the same oscillator displacements, calculated from seismic code and from the rockburst records with given ground velocity.

Open Access This article is distributed under the terms of the Creative Commons Attribution Noncommercial License which permits any noncommercial use, distribution, and reproduction in any medium, provided the original author(s) and source are credited.

\section{References}

Arias A (1970) A measure of earthquake intensity. In: Hansen RI (ed) Seismic design of nuclear power plants. MIT Press, Cambridge, MA

Chopra AK (1995) Dynamics of structures with application to seismic engineering. Prentice-Hall, New Jersey DIN 41-50 (1975), Vornorm, September 1975 Erschütterungen im Bauwesen

Dowding CH (1996) Construction vibrations. Prentice-Hall, New Jersey

EN 1998-1 (2005), Eurocode 8: design of structures for earthquake resistance

García-Mayordomo J, Faccioli E, Paolucci R (2004) Comparative study of the seismic hazard assessments in European National seismic codes. Bull Earthquake Eng 2(1):71-73

Gibowicz SJ, Kijko A (1994) An introduction to mining seismology. Academic Press, San Diego

Hadjian AH (1993) The Spitak, Armenia earthquake of 7 December 1988-why so much destruction. Soil Dyn Earthq Eng 12:1-24

Johnston JC (1992) Rockbursts from a global perspective. In: Knoll P (ed) Induced seismicity. Balkema, Rotterdam, Brookfield, pp 63-78

Khandelwal M, Singh TN (2007) Evaluation of blast-induced ground vibration predictors. Soil Dyn Earthq Eng 27:116-125

Kijko A, Lasocki S, Graham G (2001) Non-parametric seismic hazard in mines. Pure Appl Geophys 158: 1655-1675

Knoll P (ed) (1992) Induced seismicity. Balkema, Rotterdam

Lu Y, Hao H, Ma G, Zhou Y (2002) Local-mode resonance and its structural effects under horizontal ground shock excitations. J Sound Vib 254(1):51-68

Mutke G, Muszyński L, Lurka A, Siata R, Logiewa H, Musiał M, Byrczek B (2000) Assesment of correctness of measurements of ground vibrations for ZG Rudna mine rockbursts (in Polish). GIG report number 42162719-123, April 2000

Paolucci R, Spinelli D (2006) Ground motion induced by train passage. J Eng Mech ASCE 132:201-210

Pomeroy PW, Best WJ, McEvilly (1982) Test Ban Treaty verification with regional data-a review. Bull Seismol Soc Am 72B:89-129

Siskind DE, Stagg MS, Kopp JW, Dowding CH (1980) Structure response and damage produced by ground vibrations from surface mine blasting. Report of Investigation RI 8507, US Bureau of Mines

Trifunac MD, Brady AG (1975a) On the correlation of seismic intensity scales with the peaks of recorded strong ground motion. Bull Seismol Soc Am 65(1):139-162

Trifunac MD, Brady AG (1975b) A study on the duration of strong earthquake ground motion. Bull Seismol Soc Am 65:581-626

Van Eck T, Goutbeek F, Haak H, Dost B (2006) Seismic hazard due to small-magnitude, shallow-source, induced earthquakes in The Netherlands. Eng Geol 87:105-121

Zembaty Z (2004) Rockburst induced ground motion—a comparative study. Soil Dyn Earthq Eng 24:11-23 
Zmbaty Z (2006) Estimation of seismic intensity of the strong rockburst of May 21st 2006 and conclusions for the future, (in Polish) report BE-14/06, Opole University of Technology, pp 1-74

Zembaty Z, Kokot S (2007) Determination of equivalent inertia forces of the kinematic excitations to design new buildings in the LGOM Copper Basin (in Polish) report BU-14/07, for "KGHM CUPRUM", Opole University of Technology, pp 1-50 